\title{
Sociological analysis of the content of media coverage on the "Social Committee for AIDS (SKA)" Facebook profile
}

\author{
Ewa Dąbrowska-Prokopowska ${ }^{1}$, Magdalena M. Suchacz ${ }^{2}$ \\ ${ }^{1}$ Department of Contemporary Polish Society, Institute of Sociology and Cognitive Science, Faculty of History and Sociology \\ of the University of Bialystok, Poland \\ ${ }^{2}$ Department of Infectious and Tropical Diseases and Hepatology, Medical University of Warsaw, Poland
}

\begin{abstract}
Introduction: Social networks are appropriate tools for providing information or creating a proper image of specific organizations or institutions, including those related to health care. They also make it possible to overcome communication barriers in such topics as promoting knowledge related to the diagnosis and prevention of human immunodeficiency virus (HIV) infection. In the following work, the authors sought to present a sociological analysis of the content and form of media coverage on the "Social Committee for AIDS (SKA)" profile on Facebook in the time interval selected for the study.

Material and methods: This qualitative study is based on the method of analyzing the content of the media message of the selected profile on the social networking site Facebook. The research was performed based on the entries from August and September 2018 posted on the profile of the "Social Committee on AIDS (SKA)" on Facebook.

Results: The studied profile had a significant number of 1541 likes and 1509 marked possibilities to observe it. The analysis of contents concerned in total 32 entries posted on the profile in August-September 2018. All research hypotheses have been verified positively.

Conclusions: Creating media messages targeted at the group of people at risk of HIV infection has above all to meet such criteria as: be adapted to the contemporary requirements of creating messages on social networking sites on the Internet, be created in the proper context of contemporary Polish society, underline high professional competence of medical staff and scientific achievements in the field of HIV/ acquired immunodeficiency syndrome (AIDS).
\end{abstract}

HIV AIDS Rev 2019; 18, 1: 70-73

DOI: https://doi.org/10.5114/hivar.2019.83685

Key words: sociological analysis, media messages, Facebook, HIV, Polish society.

\section{Introduction}

In modern societies, new media, including the Internet, perform various functions: information, education, advertising and persuasion [1]. Social networks are appropriate tools for providing information or creating a proper image

Address for correspondence: Magdalena M. Suchacz, Department of Infectious and Tropical Diseases and Hepatology, Medical University of Warsaw, 37 Wolska St., 01-201 Warsaw, Poland, e-mail: m.dabrowska@op.pl

of specific organizations or institutions, including those related to health care. They also make it possible to overcome communication barriers in such topics as, for example, promoting knowledge related to the diagnosis and prevention of human immunodeficiency virus (HIV) infection. Designing appropriate media messages aimed at achieving

Article history:

Received: 13.11 .2018

Received in revised form: 27.12.2018

Accepted: 05.02.2019

Available online: 10.03.2019
International Journal of HIV-Related Problems

HIV \& AIDS

$R$ e vi e w 
appropriate educational or persuasive activities is not a simple matter, especially in the case of messages which are treated as unacceptable in a given society.

In the following work, the authors sought to present a sociological analysis of the content and form of media coverage on the "Social Committee for AIDS (SKA)" profile on Facebook in the time interval selected for the study. It seems that despite the analysis of only one profile, it is possible to draw from it implicitly wider conclusions that will be useful in attempting to properly design media messages targeted at a group of people at risk of HIV infection.

\section{Material and methods}

This qualitative study is based on the method of analyzing the content of the media message of the selected profile on the social networking site Facebook. Analysis of media content is a technique used in sociology to study the content and form of specific textual and visual messages that take place in a specific social context. Using content analysis, the researcher seeks to answer the question "who says what, to whom, why, and with what effect?" [2]. This study was based on the analysis of a selected media message taking place in the specific context of the Internet and a social networking site. According to Dominik Batorski, "it also enables the collection of various types of data, content and information" [3].

The study applied a holistic selection of the sample related to the analyzed time period. As a result, all entries on the selected profile were analyzed within a specified time interval of two months, counted from the day the research started. The research was performed based on the entries from August and September 2018 posted on the profile of the "Social Committee on AIDS (SKA)" on Facebook.

The study used two types of media content coding. Such action is aimed at obtaining, on the one hand, a high level of reliability, and on the other, an adequate level of depth of explaining the analyzed social phenomena. The applied coding of explicit content of the analyzed message was based on the counting of analytical concepts included in the research hypotheses. Coding of the hidden content of the message was based on the analysis of the entire research material, which in effect served to broaden the interpretation of the results obtained from the applied open coding.

\section{Results}

The "Social Committee for AIDS (SKA)" profile on Facebook is presented by its authors as a non-government organization working in the area of HIV/acquired immunodeficiency syndrome (AIDS) issues and sexually transmitted infectious diseases. The major aims of the profile and the organization itself concern mainly education targeted at "specific social and professional groups, local self-governments and opinion-forming circles and spreading information related to the risk of HIV infections and the way of avoiding it as well as the psychosocial dimension of the epidemic, in particular considering the promotion of human rights in the area of social, legal and cultural aspects of HIV/AIDS" [4]. According to the information on the profile, the site is also targeted at various professional groups, including physicians and nurses dealing with HIV-infected patients.

On 27 September 2018, the studied profile had a significant number of 1541 likes and 1509 marked possibilities to observe it. It can also be noted that the profile had the highest grade of 5.0, yet it was based on the result of only 7 reviews.

The analysis of contents concerned in total 32 entries posted on the profile in August-September 2018. The number of comments recorded under the entries comes from the day of 26 September 2018.

All research hypotheses have been verified positively (Table 1).

The "Social Committee for AIDS (SKA)" profile on Facebook in the applied form of accessible contents is in accordance with the requirements related to the effective design of messages on social networking sites. The uniqueness of social networking sites on the Internet is mainly based on short and visually attractive announcements. Such activities aim at focusing the user's attention on an attractive form of message, at the same time minimizing the information noise which surrounds the user. A significant role in this case is played by a proper ability to visualize specific announcements using emoticons, graphics, photographs or films. The message presented in the entries on the studied profile fulfills the requirements of a message visually attractive for the recipient. Most of the entries have photographs and numerous emoticons. It is worth emphasizing that emoticons frequently express not only specific emotions connected with the content of the entry (e.g. smile, pride, terror), but are also a form of graphic presentation of the problem of HIV infection (emoticon of red ribbon) and LGBT (Lesbian, Gay, Bisexual, Transgender) environment (emoticon of rainbow flag).

Table 1. Results of analysis of the context of media coverage on the studied profile on Facebook

\begin{tabular}{l|c}
\hline Categories & $\begin{array}{c}\text { Number } \\
\text { of entries }\end{array}$ \\
\hline Entries with photographs/pictures & 22 \\
\hline Entries with films & 1 \\
\hline Entries with hashtags & 11 \\
\hline Entries with emoticons & 22 \\
\hline Entries in the form of photographs/pictures & 6 \\
\hline Statistics connected with HIV/AIDS & 4 \\
\hline Workshops for HIV-infected people & 7 \\
\hline Sex education & 11 \\
\hline Advisory centers & 4 \\
\hline LGTB movement & 6 \\
\hline Workshops for people from advisory centers & 2 \\
\hline Tests for HIV infection & 5 \\
\hline Comments & 8 \\
\hline \multicolumn{2}{l}{ Sources: Own study. Number of entries: 32 (August-September 2018) }
\end{tabular}


What can be seen on the profile is that the form of films is not used very often, except for one case. The film content was constructed in the form of "curiosities", in this case connected with the production of condoms. Therefore, the film content is not directly connected with educational activities which are the aim of the organization, but is part of a wider created image of an attractive and visually interesting message. It can be said that the content of the film refers to the chief aim defined in the description of the studied profile and related to sex education, creating at the same time a logical script of the whole media message. Consequently, it can be said that the authors of the studied profile do not think that the only effective form of sex education and HIV-related topics is the use of entries which only directly concern the issues. On the studied profile the authors are attempting to build an attractive platform for Internet communication for the user, but not only a "cool" medium of providing formal information.

The content of photographs in the studied entries frequently presents the activity of people from the association or advisory centers and photographs of conducted training. It should be stressed that the photographs of training or advisory centers show their employees in a less formal way and emphasize their openness to patients. In the case of pictures there are usually simple graphics concerning the topics of workshops which present statistics of HIV/AIDS and the logo of the association. An important element in increasing the reach and visibility of entries on social networking sites is the use of hashtags, which are words preceded by the symbol "\#”. Hashtags make it possible to properly sort and search news by specific key words on social networking sites. Their proper use enables specific companies and associations to reach a narrow circle of users who look for specific contents on social networking sites. Using hashtags allows for increasing the reach and the awareness of the make and promoting specific topics. In the case of the studied profile, hashtags are used mainly in promoting modern sex education (\#sexedpl) and issues related to sex contacts after using drugs (\#cojestbrane). It is worth emphasizing that topics about HIV infections are not marked with hashtags. However, it can be assumed that the contents of the abovedescribed activities raise the issue of HIV infections.

The contents of entries in the studied profile are most often related to sex education and workshops for HIV-infected people. The contents concerning sex education concern, on the one hand, the promotion of Anja Rubik's book and activities within the action entitled "Sexedpl", and on the other, refer to the action connected with the issues of sex contacts after using drugs. It is worth emphasizing that in promotion of the action "cojestbrane" in the entries on the studied profile the engagement of LGBT associations, whose activities are targeted at individual advisory and education-motivation groups, are often stressed. In contents of entries concerning issues of sex after using drugs the following phrases are often used: "anonymity, "lack of assessment", "help", "without moralizing".

Workshops for HIV-infected people concern most frequently two topics: firstly, the topics connected with the issue of sex relations of $\mathrm{HIV}(+)$ people, and secondly, the topics of diseases that can hinder everyday functioning of infected people, e.g. obesity, diabetes, cancers. The descriptions of workshops often emphasize the importance of increasing the comfort of life for HIV-infected people and the necessity of applying proper prevention.

On the studied profile the issue connected directly with tests for HIV infections is discussed in two forms. The first is simple graphics designed in the form of "curiosities", that is simple sentences concerning results of scientific research. The following entries provide an example of such activity: "Results of tests for HIV can be obtained in 15 minutes", "HIV infection can be detected as early as after 15 days from the exposure to the virus". The second form is the promotion of advisory and diagnostic centers. It is worth emphasizing that the promotion of these centers in the entries is frequently described by the following phrases: "anonymously", "without judging", "free of charge", "LGTB friendly".

Comments below the studied entries appear very rarely, despite the fact that the studied profile has a significant number of likes and observations. Comments were visible only under 8 out of 32 studied entries. The post concerning the death and funeral of a person connected with the Social Committee for AIDS had the largest number of entries. In the case of this entry the users extended condolences and emphasized the role of the deceased person in education about HIV and AIDS issues. Under the entry 123 comments were recorded. As for the remaining entries, the ones with the most comments concerned the action "What is taken?" and the issues of sex activities after taking drugs and the action of a wider sex education within Anja Rubik's project. In these cases there were fewer comments (2-3), which underlined mainly the need for introducing such education activities in Polish society. It should be stressed that on the studied profile there were no comments under entries directly concerning workshops for $\mathrm{HIV}(+)$ patients or presented statistics. An exception to this rule is one person's comment about whether new generation tests are used in detecting HIV. Comments of users, limited only to positive emoticons, appeared also under an entry and a photograph concerning duties in the advisory center. There was also one comment, which was not connected with the content of training, under the entry concerning "chemsex" (sex activity after using drugs) in Poland.

\section{Discussion}

The analysis of the content of media coverage created on the "Social Committee for AIDS" profile is only a fragment of a wider social discourse carried out on the subject of HIV virus infections in Polish society. The conducted research leads to interesting and wider conclusions which draw attention to the demand of HIV patients for a certain form of communication with physicians and medical staff. The number of people undertaking activities directed at a contact with the physician depends on the way the information about diagnostic centers is posted, and the speed 
the HIV tests are done or HIV victims are treated. In order to obtain a high level of attractiveness and visibility of particular information as well as to reach specific groups of recipients, it is necessary to apply effectively modern information technologies, including social networking sites. Using Facebook for posting important information or creating a specific image of medical institutions dealing with diagnostics and treatment of HIV victims requires application of appropriate techniques. It can be noted on the studied profile that information posted on it is created in an attractive way for the recipient as the level of posts on it is very high due to simple graphic forms, such as emoticons, pictures and photographs. Such activities are vital for two reasons. Firstly, thanks to them the visualization of posts is increased, which makes them more visible for the users of Facebook. Secondly, they also serve to soften the image of physicians and medical staff who work at consultation and diagnostic centers. Furthermore, the proper use of hashtags enables the users to search more easily for information which is important for them.

It is crucial to create in the media coverage a proper image of physicians and medical staff dealing with the treatment of HIV patients. It should be emphasized that in Polish society it is generally believed that physicians despite the high level of their professional competence are not a group which is perceived in a positive way. This is confirmed in the survey of CBOS conducted on a representative sample of Poles in 2016 , when $49 \%$ of respondents agreed with the statement that physicians and medical staff treat patients with kindness and care. Moreover, only $24 \%$ of respondents said that diagnostic tests which they need can be done fast and without greater difficulties [5]. The presented results show that according to the respondents, the weakest point of the Polish health care is the availability of diagnostics and consultant physicians as well as the quality of applied treatment including the creation of appropriate conditions of psychological comfort for patients. In the case of HIV-infected people or functioning in groups at risk of infection in future, there can also be noted quite a strongly experienced discomfort caused by an intense dislike of homosexual people in Polish society, which is confirmed by the results of quantitative studies. According to the results of the CBOS survey of 2017, only $16 \%$ of respondents think that homosexuality is a normal thing [6]. As a result, the environment of homosexual people, being a group at risk of HIV infection, has difficulties in free communication and exchange of information in this respect. Additionally, homosexual people feel anxieties about experiencing potential dislike shown by physicians and medical staff because of their sexual orientation. In the context of the above discussion, it should be emphasized that the Internet is a good medium that makes it possible to create a positive, warm, and not appraising image of physicians and medical staff from diagnostic and advisory centers. This results from the fact that the modern Internet dominated by social networking sites guarantees its users, on the one hand, relative anonymity, and on the other, free communication and access to important information.

\section{Conclusions}

Creating media messages targeted at the group of people at risk of HIV infection has above all to meet two criteria. Firstly, its form has to be adapted to the contemporary requirements of creating messages on social networking sites on the Internet by applying appropriate visual and graphic forms. Secondly, it is vital to write the created messages in the proper context of contemporary Polish society, where, on the one hand, the level of satisfaction with the functioning of health care is rather low, and on the other, the level of approval for sexual orientation is low. Moreover, it is vital to stress the high professional competence of physicians and medical staff in the field of HIV/AIDS and scientific achievements in treating $\mathrm{HIV}(+)$ patients. Such activities make it possible to increase the level of reliability of the presented media messages, considering the fact that the contents provided to Internet users usually have a low level of reliability and their simplified form generates the situation that the presented contents are selective and inaccurate [7].

\section{Conflict of interest}

The authors declare no potential conflicts of interest with respect to the research, authorship, and/or publication of this article.

\section{References}

1. Dobek-Ostrowska B, Winiszewski R. Teoria komunikowania publicznego i politycznego. Wydawnictwo Astrum, Wrocław 2002; 120-121.

2. Babbie E. Badania społeczne w praktyce. Wydawnictwo Naukowe PWN, Warszawa 2003; 342.

3. Batorski D. Prowadzenie badań przez Internet - podstawowe zagadnienia metodologiczne. Studia Socjologiczne 2006; 3: 102.

4. https://www.facebook.com/pg/spolecznykomitet/about/?ref= page_internal

5. https://www.cbos.pl/SPISKOM.POL/2016/K_113_16.PDF

6. https://www.cbos.pl/SPISKOM.POL/2017/K_174_17.PDF

7. Szarek A. Rozwój społeczeństwa informacyjnego a problem asymetrii informacji na rynku. Studies \& Proceedings of Polish Association for Knowledge Management 2011; 51: 133. 